regard to his remarks about the lava flows from a crater, though I am by no means an authority upon this subject, such as Dr. Johnston-Lavis, I would beg to point out that the lava from the crater of Skaptar Jokul in the year 1783 formed two main streams which flowed for a distance of forty to fifty miles each, and varied in thickness or depth from 600 to I000 $\mathrm{ft}$. Now I cannot help thinking that such streams, only so much bigger, might have flowed from the craters of the moon, and it is well known that enormous floods have issued from volcanoes in the Sandwich Islands without much eruption of rocky, or pumaceous débris, which might hide the effect of the lava, as Dr. Johnston-Lavis suggests, though Prof. Pickering puts forward the suggestion that it is some material, such as pumice, which we see in the moon's rays. Apart from which geologists tell us that apparently in prehistoric times lava seems to have issued from vertical fissures, and deluged large areas, as is well seen in the great basalt plain of Snake River, Idaho, North America. Assuming that these fissures were caused by the contraction of the earth's outer crust when cooling, and again comparing the moon with the earth, we at least come to Nasmyth's wellknown theory as regards these ray systems, though the manner in which these peculiar phenomena radiate from the craters still seems to suggest to me the same actions which took place from Skaptar Jokul, and in the Sandwich Islands. However, assuming Dr. Johnston-Lavis to be correct in his objections to this theory, I should like to know if he considers Nasmyth's theory any more likely to solve this interesting problem?

Then with reference to the meteorite theory, it seems to me that this scarcely satisfies all the objections. In the first place, these rays are in many cases as wide as ten to twenty miles, and of a very considerable length, and it would take a meteor or other body of excessive size to cause such markings, apart from which the speed would have to be truly prodigious, and, however horizontally the object was approaching the lunar surface, the gravitational attraction, though comparatively slight, would tend to divert the path into a vertical one to some other portion of the surface. Again, it is a curious coincidence that by far the greater number of these rays radiate from the principal craters, and if the meteorite theory is correct, how is it they crossed such a huge-walled crater as Clavius without apparently breaking down its walls, though leaving their marks? The rills and clefts certainly lend themselves to this theory, though when we consider the Sirsalis cleft, 300 miles long, and that there are no fewer than forty in the interior of Gassendi, it becomes difficult to explain even these.

I certainly agree with Dr. Johnston-Lavis, that a practical astronomer with a high-power instrument ought to collaborate with a thoroughly practical vulcanologist, when perhaps some satisfactory explanation would be arrived at. Until then, I am afraid things will have to remain as they are.

C. Hubert Plant.

Lichfield Road, Walsall, February 10.

\section{The Discovery of Australia.}

IN a note in NATURE of November 27, I9I3 (p. 379) relative to the Houtman's Abrolhos Islands, the remark is made:- "The wreck of the Dutch East India Co.'s ship, the Batavia, under the command of Capt. Pelsart, in 1629 , is said to have led to the first recorded discovery of Australia."

Without entering into the vexed question of who first discovered Australia, I may point out that there are records of more than a dozen visits of Dutch ships and one English shio to the northern and NO. 23 I3, VOL. 92] western coasts of Australia before 1629. In fact, the general outline of the whole of the present State of Western Australia and of the Gulf of Carpentaria was known to the Dutch before that date.

The Abrolhos Islands were discovered by the ships Dordrecht and Amsterdam, under the command of Frederik de Houtman, whose name they still bear, in 1619 (vd. Heeres, "The Part Borne by the Dutch in the Discovery of Australia"). They were rediscovered by the ship Tortelduif in 1624 , and the East India Co. recognised their danger to navigation, and had accordingly issued warnings to the commanders of all its vessels before Pelsart sailed from Holland.

From a scientific point of view the wreck of the Batavia is of most interest, because it led to the discovery of the first member of the kangaroo family, viz., the Dama Wallaby, Macropus eugenii, which is plentiful on the two largest islands of the group.

As it is generally supposed that the first discovery of the kangaroo was made by Sir Joseph Banks on Captain Cook's first voyage in 1770 , I think that zoologists may find Pelsart's account of this smaller species, written nearly I50 years earlier, of interest.

He says :- "We found in these islands large numbers of a species of cats, which are very strange creatures; they are about the size of a hare, their head resembling the head of a civet-cat; the forepaws are very short, about the length of a finger, on which the animal has five small nails or fingers, resembling those of a monkey's forepaw. Its two hind legs, on the contrary, are upwards of half an ell in length, and it walks on these only, on the flat of the heavy part of the leg, so that it does not run fast. Its tail is very long, like that of a long-tailed monkey; if it eats, it sits on its hind legs, and clutches its food with its forepaws, just like a squirre! or monkey.

"Their manner of generation or procreation is exceedingly strange and highly worth observing. Below the belly the female carries a pouch, into which you may put your hand; inside this pouch are her nipples, and we have found that the young ones grow up in this pouch with the nipples in their mouths. We have seen some young ones lying there, which were only the size of a bean, though at the same time perfectly proportioned, so that it seems certain that they grow there out of the nipples of the mammæ, from which they draw their food, until they are grown up and are able to walk. Still, they keep creeping into the pouch even when they have become very large, and the dam runs off with them when they are hunted." W. B. Alexander.

The Western Australian Museum and Art Gallery, Perth, Western Australia, January Io.

\section{DAILY SYNOPTIC CHARTS OF \\ THE NORTHERN HEMISPHERE AND ABSOLUTE UNITS.}

$\mathrm{O}^{\mathrm{N}}$ January $\mathrm{I}$ of this year, as already mentioned in the Notes of the issue of Nature for February 5, the Weather Bureau of the United States commenced the issue of a daily weather map of the northern hemisphere, compiled from observations received daily at Washington by telegraph.

In addition to the regular reports from the United States and Canada, represented in the well-known daily weather map of the bureau, reports are obtained from upwards of forty stations, which are sufficiently distributed in latitude and longitude to form the basis of a chart of isobars and isotherms for the northern hemi- 
sphere. The information is given on the back of the daily bulletin, and the Weather Bureau is to be congratulated upon being the first to publish a map showing the distribution of pressure and temperature over a hemisphere on the day of issue.

It rests with the bureau, or with some still more enterprising institute if there be one, to add the available observations from the southern hemisphere, and realise what everyone who thinks about the subject knows to be the most sure basis for the study of the daily weather, viz., a daily map of the main features of the distribution of pressure and temperature over the globe.

Practically no lines are drawn on these maps for latitudes lower than $25^{\circ}$, and it is interesting to speculate as to what sort of characteristics a synoptic chart of the equatorial regions would show if it could be drawn. North of $25^{\circ}$ the rotation of the earth makes it possible for pressure differences represented by "parallel isobars" to be sufficiently permanent to be charted, while ordinary centrifugal action makes "circular" isobars also equally possible. Hence on a chart for temperate and polar regions, isobars may take any shape between the small circle of a cyclonic depression and the great circle of "straight" isobars; but in the equatorial region there is no place for "parallel isobars," as they are understood further north, because the influence of the rotation of the earth is too feeble; the winds required to balance isobars such as those to which we are accustomed would be prodigious. Consequently a pressure distribution sufficiently permanent to be mapped could only be made up of "circular" isobars, and therefore a chart of isobars for part of the equatorial region ought to be a collection of small circles with whatever may be necessary to represent the diurnal variation. It would be interesting to have this conclusion veritied, and the transition between the region of circular isobars and the region of straight isobars carefully explored.

Variations of pressure, small in magnitude, but associated with weather changes, are shown as irregularities in the course of the well-known diurnal variation, on barograms for equatorial regions, and the translation of a collection of barograms into synoptic charts is an attractive problem. It would presumably tell us what the meteorological conditions would be if the earth were fixed and the sun went round it in twentyfour hours as the ancients used to suppose.

One of the striking features of the maps now issued by the Weather Bureau is that for the first time in the history of official meteorological institutions, c.g.s. units of pressure and the absolute scale of temperature are used for a daily issue of charts. The isobars are figured for every five millibars, and the isotherms for every ten or five degrees on the centigrade scale measured from $273^{\circ}$ below the freezing point of water.

This is indeed a remarkable step towards the unification of the methods of expressing pressure over the globe, and it has been immediately followed by the Meteorological Office in the corresponding charts which are published in the weekly weather report. The office figures the centibars, while the bureau figures the millibars, but that is only a matter of decimal point.

Millibars are in future to be used, though not exclusively, for the international publication of the results of the investigation of the upper air, so that while it now seems likely that before many years are passed we may see a daily synchronous chart for the globe, and really begin to study weather as it ought to be studied, we may at the same time expect to take leave of the inch and the millimetre as measures of pressure. They certainly have had a very long innings on a side to which they did not properly belong, and it will be interesting to see how the more scientific measure of pressure in pressure-units will adapt itself to practical requirements. The Meteorological Office is to make use of c.g.s. units of pressure for the Daily Weather Report on May I of the current year, and the preparations for that event have already placed some well-known facts in a curious light. The task which during the last sixty years we have been setting to British instrument-makers is as follows:- "Construct a barometer which will give a true pressure reading when the whole instrument is in latitude $45^{\circ}$, the mercury at $273^{\circ} \mathrm{A}$., and its brass case at $290^{\circ}$ A." Continental makers have had a problem that sounds simpler, viz. to construct a barometer which will give a true pressure reading when the instrument and its case are in latitude $45^{\circ}$ at $273^{\circ} \mathrm{A}$. The figures show that if instrument-makers were to make a barometer which was correct at the equator at the freezing point of water, it would be correct in latitude $45^{\circ}$ at the ordinary air-temperature of $289^{\circ} \mathrm{A}$. $\left(6 \mathrm{r}^{\circ} \mathrm{F}\right.$.) and at the poles at $305^{\circ} \mathrm{A} .\left(89^{\circ} 6^{\circ} \mathrm{F}\right.$.). So for each latitude there would be a temperature within the common range for which the readings were true pressures. At other temperatures, of course, a correction would be required.

W. N. S

\section{THE RECENT SEISMOLOGICAL DISTURB- ANCES IN SOUTH JAPAN.}

$\mathrm{N}$ the accompanying figure is reproduced, on about half the original scale, an interesting seismogram received from Prof. A. Belar, of Laibach, through the courtesy of the foreign editor of the Daily Mail. The earthquake in question occurred on the morning of January 12 , and was recorded by a Galitzin seismograph with electromagnetic damping. The times indicated on the diagram are referred to mean time of central Europe, which is one hour in advance of Greenwich time. In a second letter, Prof. Belar gives Ioh. 40m. 35s. as the time of arrival at Laibach of the first preliminary tremors, and he estimates that the earthquake occurred at 6h. 29m. 2s., p.m., Japan time. ${ }^{1}$ According to

1 According to the data given by Prof. Belar in a more recent letter, it would seem that the time at the origin should be $6 \mathrm{~h}$. $30 \mathrm{~m}$. I $3 \mathrm{~s}$. (mean time of I 35 E.) p.m., which does not differ materially from that given above. 